\title{
Fracture strength, failure type and Weibull characteristics of lithium disilicate and multiphase resin composite endocrowns under axial and lateral forces
}

Gresnigt, Marco M M ; Özcan, Mutlu ; van den Houten, Mieke L A ; Schipper, Laura ; Cune, Marco S

\begin{abstract}
OBJECTIVE Multiphase resin composite materials have been advocated as an alternative to reinforced ceramics but limited information is available to date on their stability. This in vitro study evaluated the effect of axial and lateral forces on the strength of endocrowns made of Li2Si2O5 and multiphase resin composite. METHODS Sound human molars ( $\mathrm{N}=60, \mathrm{n}=10$ per group) were randomly divided into 6 groups: Group C: Control, no preparation or restoration; Group LI: Endocrown made of Li2Si2O5 (IPS e.max CAD) and Group LA: Endocrown made of multiphase resin composite material (Lava Ultimate). After decapitation and endodontic preparation, immediate dentin sealing was performed. Following CAD/CAM fabrication, their cementation surfaces were silica coated (CoJet System) and silanized (ESPE-Sil). Endocrowns were then adhesively cemented (Variolink II). All specimens were thermocycled $(\times 10,000$ cycles). While half of the specimens in each group were subjected to axial (C(A), LI(A), LA(A)), the other half was subjected to lateral static (C(L), LI(L), LA(L)) loading $(1 \mathrm{~mm} / \mathrm{min})$. Failure type and location after debonding/fracture were classified. Data were analyzed using ANOVA and Tukey's post hoc test $(\alpha=0.05)$. Two-parameter Weibull distribution values including the Weibull modulus, scale $(\mathrm{m})$ and shape $(0)$, values were calculated. RESULTS Under axial loading, mean fracture strength (N) did not show significant difference between groups: LAA (2675 \pm 588$)(a)$, LIA (2428 \pm 566$)(a)$, CA (2151 \pm 672$)(a)$ $(\mathrm{p}>0.05)$ and under lateral loading, LAL $(838 \pm 169)(\mathrm{A})$ presented significantly lower mean values than those of other groups: CL $(1499 \pm 418)(B)$, LIL $(1118 \pm 173)(B)(p<0.05)$. Both endocrown materials and the control group were more vulnerable to lateral loading than axial loading. Under axial loading, Weibull distribution presented higher shape (0) for Groups LIA (5.35) and LAA (5.08) than that of the control (3.97) and under lateral loading LIL (7.5) showed higher shape (0) than those of other groups (4.69-6.46). After axial loading, failure types were mainly cohesive in the material and after lateral loading primarily adhesive between the material and dentin for both LI and LA, most of which were repairable. SIGNIFICANCE Under axial loading, molars restored with endocrowns performed similar with both Li2Si2O5 and multiphase resin composite but the latter was less durable under lateral loading.
\end{abstract}

DOI: https://doi.org/10.1016/j.dental.2016.01.004

Posted at the Zurich Open Repository and Archive, University of Zurich

ZORA URL: https://doi.org/10.5167/uzh-127849

Journal Article

Accepted Version

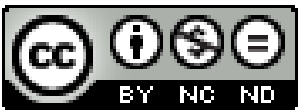

The following work is licensed under a Creative Commons: Attribution-NonCommercial-NoDerivatives 4.0 International (CC BY-NC-ND 4.0) License. 
Originally published at:

Gresnigt, Marco M M; Özcan, Mutlu; van den Houten, Mieke L A; Schipper, Laura; Cune, Marco S (2016). Fracture strength, failure type and Weibull characteristics of lithium disilicate and multiphase resin composite endocrowns under axial and lateral forces. Dental Materials, 32(5):607-614.

DOI: https://doi.org/10.1016/j.dental.2016.01.004 
Fracture Strength, Failure Type and Weilbull Characteristics of Lithiumdisilicate and

Multiphase Resin Composite Endocrowns Under Axial and Lateral Forces

Marco M.M. Gresnigt, ${ }^{a}{ }^{,}$Mutlu Özcan, ${ }^{b}$ Mieke L.A. van den Houten, ${ }^{a}$ Laura Schipper, ${ }^{a}$

Marco C. Cune, ${ }^{\text {a,c }}$

${ }^{a}$ The University of Groningen, Groningen, university Medical Center Groningen, Center for Dentistry and Oral Hygiene, Department of Fixed and Removable Prosthodontics, Groningen, The Netherlands

${ }^{b}$ University of Zurich, Dental Materials Unit, Center for Dental and Oral Medicine, Clinic for Fixed and Removable Prosthodontics and Dental Materials Science, Zurich, Switzerland

${ }^{c}$ St. Antonius Hospital Nieuwegein, Department of Oral-Maxillofacial Surgery, Prosthodontics and Special Dental Care, Nieuwegein, The Netherlands

Short title: Durability of endocrowns made of reinforced ceramic and resin composite

${ }^{*}$ Corresponding author:

Dr. Marco Gresnigt

Department of Fixed and Removable Prosthodontics

Center for Dentistry and Oral Hygiene

University Medical Center Groningen

The University of Groningen 
Antonius Deusinglaan 1

9713 AV, Groningen

The Netherlands

Tel: +31-50-363-2608; fax: +31-50-363-2696

E-mail address: marcogresnigt@yahoo.com (M. Gresnigt) 


\section{ABSTRACT}

Objectives. Multiphase resin composite materials have been advocated as an alternative to einforced ceramics but limited information is available to date on their stability. This in vitro study valuated the effect of axial and lateral forces on the strength of endocrowns made of $\mathrm{Li}_{2} \mathrm{Si}_{2} \mathrm{O}_{5}$ and vultiphase resin composite.

Methods. Sound human molars (N=60, $\mathrm{n}=10$ per group) were randomly divided into 6 groups: iroup C: Control, no preparation or restoration; Group LI: Endocrown made of $\mathrm{Li}_{2} \mathrm{Si}_{2} \mathrm{O}_{5}$ (IPS e.max ;AD) and Group LA: Endocrown made of multiphase resin composite material (Lava Ultimate). After ecapitation and endodontic preparation, immediate dentin sealing was performed. Following :AD/CAM fabrication, their cementation surfaces were silica coated (CoJet System) and silanized ESPE-Sil). Endocrowns were then adhesively cemented (Variolink II). All specimens were ermocycled (x10.000 cycles). While half of the specimens in each group were subjected to axial $\left.\tau_{A}, L I_{A}, L A_{A}\right)$, the other half was subjected to lateral static $\left(C_{L}, L I_{L}, L A_{L}\right)$ loading $(1 \mathrm{~mm} / \mathrm{min})$. Failure /pe and location after debonding/fracture were classified. Data were analyzed using ANOVA and ukey`s post-hoc test $(\alpha=0.05)$. Two-parameter Weibull distribution values including the Weibull iodulus, scale $(m)$ and shape $(0)$, values were calculated.

Results. Under axial loading, mean fracture strength $(\mathrm{N})$ did not show significant difference etween groups: $\mathrm{LA}_{A}(2675 \pm 588)^{\mathrm{a}}, \mathrm{LI}_{\mathrm{A}}(2428 \pm 566)^{\mathrm{a}}, \mathrm{C}_{\mathrm{A}}(2151 \pm 672)^{\mathrm{a}}(\mathrm{p}>0.05)$ and under lateral sading, $L A_{L}(838 \pm 169)^{A}$ presented significantly lower mean values than those of other groups: $C_{L}$ $1499 \pm 418)^{B}, L_{L}(1118 \pm 173)^{B}(p<0.05)$. Both endocrown materials and the control group were more ulnerable to lateral loading than axial loading. Under axial loading, Weibull distribution presented igher shape (0) for Groups $\mathrm{LI}_{\mathrm{A}}(5.35)$ and $\mathrm{LA}_{\mathrm{A}}$ (5.08) than that of the control (3.97) and under lateral sading $L I_{L}(7.5)$ showed higher shape (o) than those of other groups (4.69-6.46). After axial loading, ailure types were mainly cohesive in the material and after lateral loading primarily adhesive etween the material and dentin for both LI and LA, most of which were repairable. 
Significance. Under axial loading, molars restored with endocrowns performed similar with both $\mathrm{i}_{2} \mathrm{Si}_{2} \mathrm{O}_{5}$ and multiphase resin composite but the latter was less durable under lateral loading.

Keywords: CAD/CAM; Composite; Ceramic; Endocrowns; Endodontics; Hybrid materials; ithium disilicate

\section{Introduction}

Severe coronal tooth structure loss due to extensive caries or root canal therapy has been typically restored with a post and core retained full coverage crown in reconstructive dentistry. Due to the advances in adhesive technologies and materials almost two decades ago endocrown type of restorations were suggested for posterior teeth as an alternative to post and core retained ones [1]. An endocrown is a monoblock restoration that is cemented to the internal portion of the pulp chamber and to the remaining tooth margins using adhesive luting cement. Hence, their retention to the tooth is achieved through both macro- and micro-mechanical means. Endocrowns restore the anatomy, seal the root canal opening, preventing bacterial recolonization all of which eventually affect the long-term prognosis of a tooth following endodontic treatment [2].

Finite element analysis, mathematical modelling and static loading tests from in vitro studies suggest that molar teeth restored by endocrowns could withstand physiological chewing forces without fracture or debonding [3-5]. They seem to be potentially more resistant to failure than molars restored with glass fiber reinforced composite posts [3-5]. Several authors described the clinical procedure for the fabrication of endocrowns made of modern ceramics in case reports [6-9]. Shortterm clinical evaluations present promising results with respect to aesthetics and functional longevity of endocrowns made of glass ceramic with annual failures rate of 0 to $0.2 \%$ up to 12 to 35.5 months of follow up [10-12].

Recently, multiphase resin composite materials have been advocated as an alternative to reinforced ceramics since they have more biomimetic properties with similar elasticity modulus closer to tooth structure. Limited information is available to date on their durability but they 
presented promising results for occlusal onlays [13]. The present study aims to expand the current knowledge on structural durability of endocrowns.

The objectives of this in vitro study therefore were to a) compare the fracture strength of endocrowns made of $\mathrm{Li}_{2} \mathrm{Si}_{2} \mathrm{O}_{5}$ or multiphase resin composite and compare the results with natural teeth under axial and lateral forces, b) evaluate the failure types after testing. The null hypothesis tested was that material type and loading direction would not affect the fracture strength of endocrowns and the results would not differ from those of unrestored natural teeth.

\section{Material and methods}

\subsection{Specimen preparation}

The brands, types, main chemical compositions, manufacturers and batch numbers of the materials used for the experiments are listed in Table 1. Schematic description of the experimental design is presented in Fig. 1.

Sound human mandibular molars ( $N=60, n=10$ per group) of similar size and morphology, free of restorations and root canal treatment were selected from a pool of recently extracted teeth that were stored in distilled water. All teeth were screened on the presence of fractures by blue light and those with cracks were eliminated and replaced with new teeth. They were then embedded up to 1 $\mathrm{mm}$ below the cement-enamel junction (CEJ) in polyvinylchloride (PVC) tubes (height: $10 \mathrm{~mm}$; diameter: $12 \mathrm{~mm}$ ) using autopolymerizing acrylic resin (Autoplast, Condular, Wager, Switzerland) and stored in distilled water at $37^{\circ} \mathrm{C}$ until preparation [14]. The teeth were randomly divided into 3 groups: Group C: Control, no preparation or restoration; Group LI: Endocrown made of $\mathrm{Li}_{2} \mathrm{Si}_{2} \mathrm{O}_{5}$ (IPS e.max CAD, Ivoclar Vivadent, Schaan, Liechtenstein) and Group LA: Endocrown made of multiphase resin composite material (Lava Ultimate, 3M ESPE, St. Paul, Minnesota, USA).

\subsection{Tooth preparation}

Specimens in Groups LI and LA were scanned (Cerec Omnicam, Sirona, Bensheim, Germany) and the data were stored in the Cerec database (version 3.85, Sirona Dental Systems, Bensheim, 
Germany) in order to be able to restore the teeth to their original anatomy after preparation. An impression (Express 3M ESPE, Seefeld, Germany) was made from each tooth to facilitate the fabrication of a provisional restoration after preparation. Subsequently, the teeth were decapitated to a level $1 \mathrm{~mm}$ above the CEJ. Access to the root canal was opened with respect to the anatomy of the pulp chamber. Root canals were prepared using manual instrumentation to a depth of $10 \mathrm{~mm}$ relative to the margin of the tooth up to size no. 30 file with an average diameter of $0.9 \mathrm{~mm}$ (Kflexofile, Dentsply, Milford, USA). Then, the prepared dentin surfaces were sealed with the so-called Immediate Dentin Sealing (IDS) [15]. This procedure involved etching dentin with $38 \% \mathrm{H}_{3} \mathrm{PO}_{4}$ (Ultraetch, Ultradent, St Louis, USA) for 15 seconds, rinsing and subsequent drying for 3 to 4 seconds. A primer (OptiBond FL, Kerr, Orange, USA) was applied for 15 seconds followed by 3 to 5 seconds of suction drying. After that adhesive resin (OptiBond FL, Kerr) was carefully applied onto the surface for 20 seconds, followed by 20 seconds of polymerization using an LED polymerization device (Bluephase, Ivoclar Vivadent) from a distance of $2 \mathrm{~mm}$. The output of the polymerization device was $1000 \mathrm{~mW} / \mathrm{cm}^{2}$ throughout the experiment (Bluephasemeter, Ivoclar Vivadent). The entrance of the root-canals and undercuts in the pulp chamber were covered with a flowable composite resin (Tetric Flow, Ivoclar Vivadent) followed by 20 seconds of photo-polymerization. After application of glycerin gel (Panavia Oxyguard, Kuraray, Osaka, Japan), the surface was again photo-polymerized for 40 seconds and finally, the gel was rinsed away. The IDS layer was checked for the presence of voids and excess adhesive resin was removed under the microscope (Opmipico, Zeiss, Oberkochen, Germany).

The decapitated specimens were scanned again using the Cerec scanner (Cerec Omnicam, Sirona, Bensheim, Germany). Endocrowns were designed and milled (Cerec MC XL, Sirona) according to the original anatomy that was previously stored in the database (Figs. 2a-b). Afterwards, a provisional restoration was made (Protemp 4, 3M ESPE, Seefeld, Germany) and cemented (TempBond, Kerr). The specimens were stored in water for another 2 weeks to simulate the typical clinical situation for the provisional phase of indirect restorations. 


\subsection{Adhesive cementation}

After 2 weeks, the provisional restorations were carefully removed and the fit of the restorations checked with a probe. The cementation surface of the lithium LI restorations were etched for 20 seconds with $4.9 \%$ hydrofluoric acid (IPS ceramic etch, Ivoclar Vivadent), followed by 30 seconds of rinsing with water. The restorations were ultrasonically cleaned (Emag, Valkenswaard, The Netherlands) in distilled water for 3 minutes, dried and silane coupling agent was applied (Monobond Plus, Ivoclar Vivadent) that was further activated at $100^{\circ} \mathrm{C}$ for 60 seconds. Finally, adhesive resin was applied to the surface (Syntac Adhesive, Ivoclar Vivadent) and air thinned.

The cementation surface of LA endocrowns were silica coated (CoJet, 3M, ESPE) using a chairside air-abrasion device (Dento-Prep ${ }^{\mathrm{TM}}$, RØNVIG A/S, Daugaard, Denmark) from a distance of $10 \mathrm{~mm}$, angle of $45^{\circ}$ and 2 bar pressure until the surface became matt for 5 seconds. Silane coupling agent was applied (ESPE Sil, 3M ESPE) and further activated at $100^{\circ} \mathrm{C}$ for 60 seconds. Finally, adhesive resin was applied to the surface (Syntac Adhesive, Ivoclar Vivadent) and air thinned.

On the tooth surface the IDS layer was silica coated as described above (CoJet, 3M ESPE). Enamel was etched with $38 \% \mathrm{H}_{3} \mathrm{PO}_{4}$ (Ultraetch, Ultradent) for 30 seconds, rinsed and dried for 30 seconds. Silane coupling agent was applied on the IDS layer (ESPE Sil, 3M ESPE), followed by primer (Syntac Primer, Syntac Adhesive, Ivoclar Vivadent) and adhesive resin (Heliobond, Ivoclar Vivadent) application on both the tooth and the restoration surfaces. The dual polymerizing cement (Variolink II, Ivoclar Vivadent) was mixed and distributed on the cementation surface of the restoration. The endocrown was placed on the tooth under standardized occlusal pressure (50 N) using a custom-made device. Excess cement was removed from the margins, an oxygen inhibition gel (Liquid Strip, Ivoclar Vivadent) was applied at the margins and the specimens were photo- 
polymerized from occlusal, buccal, lingual, mesial and distal directions for 40 seconds each. Excess cement was removed and margins were finished and polished.

\subsection{Aging and fracture test}

All specimens were thermocycled (Willytec, Munich, Germany) for 10.000 times between $5^{\circ} \mathrm{C}$ and $55^{\circ} \mathrm{C}$ with a dwell time of 30 seconds in each bath. After aging, digital photos of the specimens were made.

The fracture test was performed in a Universal Testing Machine (MTS 810, Eden Prairie, USA). While half of the specimens were mounted in a metal base and the stainless steel round load cell was applied perpendicular to the occlusal plane, at the central fissure (axial loading), the other half was loaded by means of a v-shaped stainless steel load cell that was placed on the interface between the tooth-endocrown margin interface (lateral loading) (Figs. 3a-b). The maximum force to produce fracture was recorded.

\subsection{Failure analysis}

Failure sites were initially observed using a dental microscope (OPMIpico, Zeiss, Oberkochen, Germany), and digital photos were made from the specimens. Failure types were classified as follows: Type I: Cohesive failure in the endocrown material; Type II: Adhesive failure between the endocrown material and dentin; Type III: Cohesive failure in enamel/dentin; Type VI: Fracture extending to root. Failures above CEJ were considered as "Repairable" and those below Cemento Enamel Junction (CEJ) extending the root were classified as "irrepairable".

\subsection{Statistical analysis}

Kolmogorov-Smirnov and Shapiro-Wilk tests were used to test normal distribution of the data. As the data $(\mathrm{N})$ were normally distributed, 2-way analysis of variance (ANOVA) were applied to analyse possible differences between the groups using a statistical software programme (SPSS, 
PASW statistics 18.0.3, Chicago, USA). Due to significant difference $(p=0.000)$, Tukey's post hoc test was applied to compare the significant differences between groups where the fracture strength (N) was the dependent variable and endocrown materials (2 levels: LI and LA) and force direction (2 levels; axial and lateral). Maximum likelihood estimation without a correction factor was used for 2parameter Weibull distribution, including the Weibull modulus, scale $(m)$ and shape $(0)$, to interpret predictability and reliability of endocrown materials (Minitab Software V.16, State College, PA, USA). $P<0.05$ was considered to be statistically significant in all tests.

\section{Results}

Under axial loading, mean fracture strength $(\mathrm{N})$ did not show significant difference between groups: $\mathrm{LA}_{A}(2675 \pm 588)^{\mathrm{a}}, \mathrm{LI}_{\mathrm{A}}(2428 \pm 566)^{\mathrm{a}}, \mathrm{C}_{\mathrm{A}}(2151 \pm 672)^{\mathrm{a}}(\mathrm{p}>0.05)$ and under lateral loading, $L A_{L}$ $(838 \pm 169)^{A}$ presented significantly lower mean values than those of other groups: $C_{L}(1499 \pm 418)^{B}$, $L_{L}(1118 \pm 173)^{B}(p<0.05)$ (Table 2). Both endocrown materials and the control group were more vulnerable to lateral loading than axial loading.

Under axial loading, Weibull distribution presented higher shape (0) for Groups $L_{A}(5.35)$ and $L A_{A}(5.08)$ than that of the control (3.97) and under lateral loading $L I_{L}(7.5)$ showed higher shape $(0)$ than those of other groups (4.69-6.46) (Figs. 4a-b).

After axial loading, failure types were mainly cohesive in the material and after lateral loading primarily adhesive between the material and dentin for both LI and LA (Fig. 5). Irrespective of the groups the majority of the specimens were considered repairable (Fig. 6).

\section{Discussion}

This study was undertaken in order to compare the fracture strength of endocrowns made of either glassy matrix or resin composite materials to natural teeth under clinically relevant direction of forces, namely axial and lateral forces. Based on the results of this study, since material type did not show significant difference in terms of fracture strength under axial forces but under lateral forces, 
the first hypothesis could be partially accepted. On the other hand, since lateral forces decreased the fracture strength for all groups significantly compared to axial forces, the second hypothesis could be rejected.

Molar teeth with extensive loss of coronal tooth structure have traditionally been restored by means of a cast metal or fiberglass reinforced composite post and crown. Concerns regarding such a procedure include the risk of root perforation and the need for removal of sound tissue in the root canal to facilitate the room for the post material, thus weakening the tooth-root complex. Moreover, the benefit of a post in the root canal for the overall retention of the successive reconstruction in general is being questioned in recent years [16]. Clinical results from long-term studies up to 17 years with crowns cemented on composite core build-ups have failed to demonstrate the merits of a metal post on the tooth survival in the presence of adequate ferrule effect $[17,18]$. The introduction and application of fibre reinforced composite posts has not changed the view on the subject. The amount of remaining ferrule seems to be the predominant factor for tooth survival in extensively structurally compromised non-vital teeth $[19,20]$. Compared to other indirect restorative alternatives that may require root canal therapy, provision of an endocrown is a relatively easy, cost-effective procedure that requires less chairside time. In addition, supragingival margins facilitate plaque control and clinical inspection.

The results from the present in vitro study emphasize the potential of endocrowns made of either LI or LA materials to withstand considerable compressive loads that were similar to unrestored controls. The results obtained in this study were within the same range as occlusal veneers made from the same materials in another study [13]. The observed values at time of fracture under axial loading were well above the mean masticatory forces in humans ranging from approximately 600 to $900 \mathrm{~N}$ for females and males, respectively [21-23]. Axial loading may represent occlusal forces where elasticity modulus and thickness of the restorative material may be decisive for survival of a restorative material but in reality such forces are always accompanied with lateral forces during chewing function. In that respect, lateral loading and the consequent durability 
of endocrowns encompass not only inherent characteristics of the material but also the durability under shear stresses. Little is known about the magnitude of forces to the jaw or teeth from lateral direction during oral function in human but from a theoretical and validated model it is assumed that solely lateral forces lie in the order of $200 \mathrm{~N}[24,25]$, hence, considerably lower than the failure loads obtained in the present study. Yet, with the LA material the results were significantly lower than the LI. This could be attributed to inferior adhesion of the resin composite to the highly polymerized LA material that could be also confirmed by the adhesive failures. Although cementation surfaces of LA material were previously conditioned with tribochemical silica coating, obviously the obtained results did not surpass that of physico-chemical conditioning with LI material. Weibull parameters support this assumption in that $\mathrm{LI}(7.5)$ delivered the higher values than that of LA (6.46). However, under axial loading this difference between LI (5.35) and LA (5.08) was less. Nevertheless, cohesive failure types in the material after axial loading could be repaired using resin composites after appropriate conditioning of the LI or LA material $[26,27]$. On the other hand, debonded restorations experienced after lateral could be recemented using resin cements again after surface conditioning. Yet, clinical longevity of such repaired of recemented restorations is unknown but one can anticipate that torque forces in a recementation situation may be more susceptible than to repairs on the material.

One aspect that deserves discussion in this study is the use of natural teeth as control group. Preclinical and clinical survival of materials is important since the ultimate goal is to apply materials that survive as long as the natural teeth. However, the gradient and anisotrophic nature of teeth could not be directly compared with those of the artificial materials tested. Thus, interpretations for comparisons with the natural tooth should be made with caution. Nonetheless, similar trends were observed when the load type was considered, namely lateral forces created more damage in the control group similar to other materials tested. In this study, periodontal ligament was not simulated because artificial films usually used for this purpose show degradation. This would then result in displacement of the tooth during testing. Previous studies even showed that periodontal ligament 
simulation could change the fracture strength results and failure modes in a positive way in that the ligament could serve as a shock absorber $[28,29]$. In previous studies while some did not fill the canal [30], others did fill the canals with endodontic filling materials $[3,6,16]$. Although filling the canal may be considered clinically more relevant, in this study, in order to find out the material strength and their adhesion to the tooth solely, this factor was not considered. However, lack of adequate adhesion of resin cements to canal filling materials may induce cracks and debonding at the cementation interface that needs further investigation.

Aging with thermocycling has been a matter of debate in the dental literature. While some authors found no significant effect on adhesion [31,32], others did [33,34]. Its effect on bond strength is contradictory and seems to depend on the number of cycles $[35,36]$, size of the specimens $[36,37]$ and the C-factor $[38,39]$. Thus, the clinical relevancy of such aging methods has to be correlated with clinical studies in the future.

Future studies should also focus on performance of the tested materials for endocrowns under dynamic loading both axially and laterally before prospective clinical studies are commenced.

\section{Conclusions}

From this study, the following could be concluded:

1.Under axial loading, both $\mathrm{Li}_{2} \mathrm{Si}_{2} \mathrm{O}_{5}$ and multiphase resin composite used as endocrown material presented similar fracture strength but under lateral forces the latter exhibited significantly lower results.

2.Considering Weilbull parameters, characteristics of adhesion and thereby interfacial strength seems to be more reliable with $\mathrm{Li}_{2} \mathrm{Si}_{2} \mathrm{O}_{5}$ under both axial and lateral loading than multiphase resin composite for endocrown indication. 
3. After axial loading, failure types were mainly cohesive in the material and after lateral loading primarily adhesive between the material and dentin for both materials tested, providing that most of the failures were repairable.

\section{Acknowledgements}

The authors acknowledge Jeske Piëst, Ulf Schepke and Riemer Vochteloo for their assistance in fabricating the endocrowns, and extend their gratitude to 3M ESPE, The Netherlands and Ivoclar Vivadent, Schaan, Liechtenstein for generous provision of some of the materials used in this study.

\section{Conflict of Interest}

The authors of this article certify that they have no proprietary, financial, or other personal interest of any nature or kind in any product, service, and/or company that is presented in this article.

\section{References}

[1] Pissis P. Fabrication of a metal-free ceramic restoration utilizing the monoblock technique. Pract Proced Aesthet Dent 1995;7:83-94.

[2] Gillen BM, Looney SW, Gu LS, Loushine BA, Weller RN, Loushine RJ, Pashley DH, Tay FR. Impact of the quality of coronal restoration versus the quality of root canal fillings on success of root canal treatment: a systematic review and meta-analysis. J Endod 2011;37:895-902. 
[3] Biacchi GR, Basting RT. Comparison of fracture strength of endocrowns and glass fiber post-retained conventional crowns. Oper Dent 2012;37:130-36.

[4] Hasan I, Frentzen M, Utz KH, Hoyer D, Langenbach A, Bourauel C. Finite element analysis of adhesive endo-crowns of molars at different height levels of buccally applied load. J Dent Biomech 2012;3:1758736012455421.

[5] Dejak B, Mlotkowski A. 3D-Finite element analysis of molars restored with endocrowns and posts during masticatory simulation. Dent Mater 2013;29:309-17.

[6] Gohring TN, Peters OA. Restoration of endodontically treated teeth without posts. Am J Dent 2003;16:313-17.

[7] Lander E, Dietschi D. Endocrowns: a clinical report. Quintessence Int 2008;39:99-106.

[8] Biacchi GR, Mello B, Basting RT. The endocrown: an alternative approach for restoring extensively damaged molars. J Esthet Restor Dent 2013;25:383-90.

[9] Fages M, Bennasar B. The endocrown: a different type of all-ceramic reconstruction for molars. J Can Dent Assoc 2013;79:d140.

[10] Bindl A, Mormann WH. Clinical evaluation of adhesively placed Cerec endo-crowns after 2 years--preliminary results. J Adhes Dent 1999;1:255-265.

[11] Otto T. Computer-aided direct all-ceramic crowns: preliminary 1-year results of a prospective clinical study. Int J Periodontics Restorative Dent 2004;24:446-55.

[12] Bernhart J, Brauning A, Altenburger MJ, Wrbas KT. Cerec3D endocrowns--two-year clinical examination of CAD/CAM crowns for restoring endodontically treated molars. Int J Comput Dent 2010;13:141-54.

[13] Johnson AC, Versluis A, Tantbirojn D, Ahuja S. Fracture strength of CAD/CAM composite and composite-ceramic occlusal veneers. J Prosthodont Res 2014;58:107-14.

[14] Mousavinasab SM, Farhadi A, Shabanian M. Effect of storage time, thermocycling and resin coating on durability of dentin bonding systems. Dent Res J (Isfahan) 2009;6:29-37. 
[15] Magne P, Knezevic A. Simulated fatigue resistance of composite resin versus porcelain CAD/CAM overlay restorations on endodontically treated molars. Quintessence Int 2009;40:125-33.

[16] Magne P, Carvalho AO, Bruzi G, Anderson RE, Maia HP, Giannini M. Influence of no ferrule and no-post buildup design on the fatigue resistance of endodontically treated molars restored with resin nanoceramic CAD/CAM crowns. Oper Dent 2014;39:595-602.

[17] Fokkinga WA, Kreulen CM, Bronkhorst EM, Creugers NH. Up to 17-year controlled clinical study on post-and-cores and covering crowns. J Dent 2007;35:778-86.

[18] Fokkinga WA, Kreulen CM, Bronkhorst EM, Creugers NH. Composite resin core-crown reconstructions: an up to 17-year follow-up of a controlled clinical trial. Int J Prosthodont 2008;21:109-15.

[19] Creugers NH, Mentink AG, Fokkinga WA, Kreulen CM. 5-year follow-up of a prospective clinical study on various types of core restorations. Int J Prosthodont 2005;18:34-9.

[20] Pereira JR, de OF, Conti PC, do Valle AL. Effect of a crown ferrule on the fracture resistance of endodontically treated teeth restored with prefabricated posts. J Prosthet Dent 2006;95:50-4.

[21] Waltimo A, Kononen M. Maximal bite force and its association with signs and symptoms of craniomandibular disorders in young Finnish non-patients. Acta Odontol Scand 1995;53:254-8.

[22] Cosme DC, Baldisserotto SM, Canabarro SA, Shinkai RS. Bruxism and voluntary maximal bite force in young dentate adults. Int J Prosthodont 2005;18:328-32.

[23] Varga S, Spalj S, Lapter VM, Anic MS, Mestrovic S, Slaj M. Maximum voluntary molar bite force in subjects with normal occlusion. Eur J Orthod 2011;33:427-33.

[24] Koolstra JH, van Eijden TM, Weijs WA, Naeije M. A three-dimensional mathematical model of the human masticatory system predicting maximum possible bite forces. J Biomech 1988;21:563-76.

[25] Koolstra JH, van Eijden TM. Application and validation of a three-dimensional mathematical model of the human masticatory system in vivo. J Biomech 1992;25:175-87. 
[26] Özcan M, Dundar M, Comlekoglu E. Adhesion concepts in dentistry: Tooth and restorative material aspects. J Adhes Sci Tech 2012;26:2661-81.

[27] Özcan M, Koc-Dundar B. Composite-composite adhesion in dentistry: A systematic review and meta-analysis. J Adhes Sci Tech 2014;21:2209-9.

[28] Soares CJ, Pizi EC, Fonseca RB, Martins LR. Influence of root embedment material and periodontal ligament simulation on fracture resistance tests. Braz Oral Res 2005;19:11-6.

[29] Magne P, Schlichting LH, Paranhos MP. Risk of onlay fracture during pre-cementation functional occlusal tapping. Dent Mater 2011;27:942-7.

[30] Gregor L, Bouillaguet S, Onisor I, Ardu S, Kreji I, Rocca GT. Microhardness of light- and dual-polymerizable luting resins polymerized through 7.5-mm-thick endocrowns. J Prosthet Dent $\underline{2014 ; 112: 942-8 .}$

[31] Leloup G, D'Hoore W, Bouter D, Degrange M, Vreven J. Meta-analytical review of factors involved in dentin adherence. J Dent Res 2001;80:1605-14.

[32] De Munck J, Mine A, Poitevin A, Van Ende A, Cardoso MV, Van Landuyt KL, et al. Metaanalytical review of parameters involved in dentin bonding. J Dent Res 2012;91:351-7.

[33] Kumbuloglu O, Lassila LV, User A, Toksavul S, Vallittu PK. Shear bond strength of composite resin cements to lithium disilicate ceramics. J Oral Rehabil 2005;32:128-33.

[34] Nagai $T$, Kawamoto $\mathrm{Y}$, Kakehashi $\mathrm{Y}$, Matsumura $\mathrm{H}$. Adhesive bonding of a lithium disilicate ceramic material with resin-based luting agents. J Oral Rehabil 2005;32:598-605.

[35] Miyazaki M, Sato M, Onose H, Moore BK. Influence of thermal cycling on dentin bond strength of two-step bonding systems. Am J Dent 1998;11:118-22.

[36] Amaral FL, Colucci V, Palma-Dibb RG, Corona SA. Assessment of in vitro methods used to promote adhesive interface degradation: a critical review. J Esthet Restor Dent 2007;19:340-[37] De Munck J, Van Landuyt K, Peumans M, Poitevin A, Lambrechts P, Braem M, et al. A critical 
review of the durability of adhesion to tooth tissue: methods and results. J Dent Res 2005;84:11832.

[38] Price RB, Derand T, Andreou P, Murphy D. The effect of two configuration factors, time, and thermal cycling on resin to dentin bond strengths. Biomaterials 2003;24:1013-21.

[39] De Munck J, Van Landuyt K, Coutinho E, Poitevin A, Peumans M, Lambrechts P, et al. Micro-tensile bond strength of adhesives bonded to Class-I cavity-bottom dentin after thermocycling. Dent Mater 2005;21:999-1007.

\section{Captions to tables and figures:}

Tables: 
Table 1. The brands, types, chemical compositions, manufacturers and batch numbers of the materials used for the experiments. bis-GMA: Bisphenol A glycol dimethacrylate; TEGDMA: Triethylene glycol dimethacrylate; bis-EMA: Ethoxylated bisphenol A glycol dimethacrylate; UDMA: Urethane dimethacrylate; HEMA: Hydroxyethyl methacrylate; MMA: Methylmethacrylate; PMMA: Polymethylmethacrylate; GPDM; Glycerolphophate dimethacrylate; PAMM: phathalic acid monoethyl methacrylate.

Table 2. Fracture strength results (Mean \pm standard deviation) (Newton) of experimental groups after axial and lateral loading, minimum, maximum and Confidence Intervals (95\%). Same lower-case letters in each column indicate no significant differences $(p>0.05)$. For group descriptions see Fig. 1.

\section{Figures:}

Fig. 1. Flow-chart showing experimental sequence and allocation of groups.

Figs. 2a-b. a) Design of endocrown using the Cerec database (version 3.85, Sirona Dental Systems) to be able to restore the teeth to their original anatomy (Mean mesio-distal length: 10.2 $\mathrm{mm}$, Bucco-palatinal length: 10. 2mm) after preparation, b) endocrown after milling (Crown height from fissure to wall preparation outline: $2.5 \mathrm{~mm}$; Endocrown depth from preparation outline to the immediate dentin sealing: $2.3 \mathrm{~mm}$ ).

Figs. 3a-b. The position of the load cell in relation to the occlusal surface and to the endocrown-tooth interface during a) axial loading and b) lateral loading, respectively in the universal testing machine where loading was applied until fracture.

Figs. 4a-b. Probability plot with Weibull curves $(95 \% \mathrm{Cl})$ using maximum likelihood estimation, scale and shape values for all groups after a) axial loading, b) lateral loading.

Fig. 5 Frequencies of failure modes in percentages. Type I: Cohesive failure in the endocrown material; Type II: Adhesive failure between the endocrown material and dentin; Type III: Cohesive failure in enamel/dentin; Type VI: Fracture extending to root. 
Fig. 6 Frequencies of repairable (above CEJ) and irrepairable (root fractures below CEJ) failures after axial or lateral loading. 
Tables:

\begin{tabular}{|c|c|c|c|c|}
\hline Brand & Type & Chemical Composition & Manufacturer & $\begin{array}{l}\text { Batc } \\
\text { Number }\end{array}$ \\
\hline Ultraetch & Etching agent & $38 \% \mathrm{H}_{3} \mathrm{PO}_{4}$ & USA Ultradent, St Louis & 1303 \\
\hline OptiBond f & Adhesive resin & $\begin{array}{l}\text { Primer: HEMA, GPDM, PAMN } \\
\text { ethanol, water, photo-initiator } \\
\text { Adhesive: TEGDMA, UDMA, } \\
\text { GPDM, HEMA, bis-GMA, filler, pho } \\
\text { initiator }\end{array}$ & USA Kerr, Orange, CA, & $\begin{array}{l}4706 \\
4704\end{array}$ \\
\hline ESPE-Sil & $\begin{array}{l}\text { Silane coupling } \\
\text { agent }\end{array}$ & $\begin{array}{c}\text { Ethyl alcohol, } \\
\text { methacryloxypropyl, trimethoxysilar }\end{array}$ & $\begin{array}{l}\text { 3M ESPE, St. Pat } \\
\text { Minnesota, USA }\end{array}$ & 4980 \\
\hline $\begin{array}{l}\text { IPS Empre: } \\
\text { etching gel }\end{array}$ & Ceramic etching & $<5 \%$ Hydrofluoric acid & Ivoclar Vivadent & S20 \\
\hline CoJet-Sand & Blasting particles & $\begin{array}{c}\text { Aluminium trioxide partic } \\
\text { coated with silica, particle size: } 30\end{array}$ & 3M ESPE & 5066 \\
\hline $\begin{array}{l}\text { Monobond } \\
\text { Plus }\end{array}$ & \begin{tabular}{|l|} 
One component \\
primer
\end{tabular} & $\begin{array}{l}\text { Ethanol, 3- } \\
\text { trimethoxysilsylpropylmetha-crylate } \\
\text { methacrylated phosphoric acid este }\end{array}$ & Ivoclar Vivadent & $\overline{S 147}$ \\
\hline $\begin{array}{l}\text { Syntac } \\
\text { Primer }\end{array}$ & Primer & $\begin{array}{l}\text { Water, acetone, maleic acid, } \\
\text { dimethacrylate }\end{array}$ & Ivoclar Vivadent & $\overline{\mathrm{S} 12 \mathrm{C}}$ \\
\hline $\begin{array}{l}\text { Syntac } \\
\text { Adhesive }\end{array}$ & Adhesive resin & $\begin{array}{l}\quad \text { Water, gluteraldehyde, malei } \\
\text { acid, poly-ethyleneglycodi- } \\
\text { methacrylate }\end{array}$ & Ivoclar Vivadent & S15£ \\
\hline Heliobond & Adhesive resin & $\begin{array}{l}\text { bis-GMA, dimethacrylate, } \\
\text { initiators and stabilizers }\end{array}$ & Ivoclar Vivadent & $\overline{\text { S09k }}$ \\
\hline Tetric Flow & $\begin{array}{l}\text { Photo-polymeriz } \\
\text { flowable resin }\end{array}$ & $\begin{array}{l}\text { bis-GMA, UDMA, Ethoxylated } \\
\text { bis-EMA, } 16.8 \% \\
\text { Barium glass filler, } \\
\text { Ytterbiumtrifluoride, Mixed oxide } \\
48.5 \% \text {, } \\
\text { Prepolymers } 34 \% \text {, Additives } \\
0.4 \% \text { Catalysts and Stabilizers } 0.3 \% \\
\text { Pigments }<0.1 \%\end{array}$ & Ivoclar Vivadent & $\overline{\text { S08: }}$ \\
\hline CAD $^{\text {IPS e.max }}$ & $\begin{array}{l}\text { Lithium disilicate } \\
\text { Glass Ceramic }\end{array}$ & $\begin{array}{l}\quad 97 \% \mathrm{SiO}_{2}, \mathrm{Al}_{2} \mathrm{O}_{3}, \mathrm{P}_{2} \mathrm{O}_{5}, \mathrm{~K}_{2} \mathrm{O} \\
\mathrm{Na}_{2} \mathrm{O}, \mathrm{CaO}, \mathrm{F}, 3 \% \mathrm{TiO}_{2} \text {, and } \\
\text { pigments, water, alcohol, chloride }\end{array}$ & Ivoclar Vivadent & $\overline{S 041}$ \\
\hline Lava Ultim & $\begin{array}{c}\text { Mutiphase resin } \\
\text { CAD/CAM material }\end{array}$ & $\begin{array}{l}\text { Polymerized dental restorativ } \\
\text { consisting of silica nanomers }(20 \mathrm{nr} \\
\text { zirconia nanomers }(4-11 \mathrm{~nm}), \\
\text { nanocluster particles derived from } \\
\text { nanomers }(0.6-10 \mu \mathrm{m}) \text {, silane coup } \\
\text { agent, resin matrix }\end{array}$ & $3 \mathrm{M}$ ESPE & $\begin{array}{l}\text { N35i } \\
\text { N33i }\end{array}$ \\
\hline
\end{tabular}




\begin{tabular}{|l|l|l|l|r|}
\hline Variolink II & $\begin{array}{c}\text { Dual polymerize } \\
\text { resin cement }\end{array}$ & $\begin{array}{c}\text { UDMA, inorganic fillers, } \\
\text { ytterbium trifluoride, initiators, } \\
\text { stabilizers, pigments }\end{array}$ & Ivoclar Vivadent & $\begin{array}{c}\text { S09C } \\
\text { S02€ }\end{array}$ \\
\hline
\end{tabular}

Table 1. The brands, types, chemical compositions, manufacturers and batch numbers of the materials used for the experiments. bis-GMA: Bisphenol A glycol dimethacrylate; TEGDMA: Triethylene glycol dimethacrylate; bis-EMA: Ethoxylated bisphenol A glycol dimethacrylate; UDMA: Urethane dimethacrylate; HEMA: Hydroxyethyl methacrylate; MMA: Methylmethacrylate; PMMA: Polymethylmethacrylate; GPDM; Glycerolphophate dimethacrylate; PAMM: phathalic acid monoethyl methacrylate.

\begin{tabular}{|c|c|c|c|c|c|c|}
\hline \multirow{2}{*}{$\begin{array}{l}\text { Experiment } \\
\text { Groups }\end{array}$} & \multirow[t]{2}{*}{$n$} & \multirow[t]{2}{*}{ Mean (S } & \multirow[t]{2}{*}{ Minimu } & \multirow[t]{2}{*}{ Maximy } & \multicolumn{2}{|c|}{ Confidence Interval } \\
\hline & & & & & $\begin{array}{l}\text { Lowel } \\
\text { Bound }\end{array}$ & $\begin{array}{l}\text { Uppe } \\
\text { Bound }\end{array}$ \\
\hline \multicolumn{7}{|l|}{ Axial Loadir } \\
\hline $\mathrm{C}_{\mathrm{A}}$ & 1 & $2151 \pm 67$ & 661 & 3100 & 1724.3 & 2578. \\
\hline $\mathrm{LI}_{\mathrm{A}}$ & 1 & $2428 \pm 56$ & 1402 & 3233 & 2068.2 & 2788. \\
\hline $\mathrm{LA}_{\mathrm{A}}$ & 1 & $2675 \pm 58$ & 1808 & 3805 & 2301.5 & 3048 \\
\hline \multicolumn{7}{|l|}{ Lateral Load } \\
\hline$C_{L}$ & 1 & $\underset{\mathrm{C}, \mathrm{a}}{1499 \pm 41}$ & 800 & 1980 & 1199.6 & 1798: \\
\hline $\mathrm{LI}_{\mathrm{L}}$ & 1 & $\underset{\mathrm{C}, \mathrm{b}}{1118 \pm 17}$ & 862 & 1370 & 993.6 & $\overline{1241.1}$ \\
\hline$L A_{L}$ & 1 & $838 \pm 169$ & 563 & 1030 & 717.3 & 958.8 \\
\hline
\end{tabular}

Table 2. Fracture strength results (Mean \pm standard deviation) (Newton) of experimental groups after axial and lateral loading, minimum, maximum and Confidence Intervals (95\%). Same lower-case letters in each column indicate no significant differences within each loading system and same upper-case letters indicate no significant differences between loading systems $(p>0.05)$. For group descriptions see Fig. 1. 
Figures:

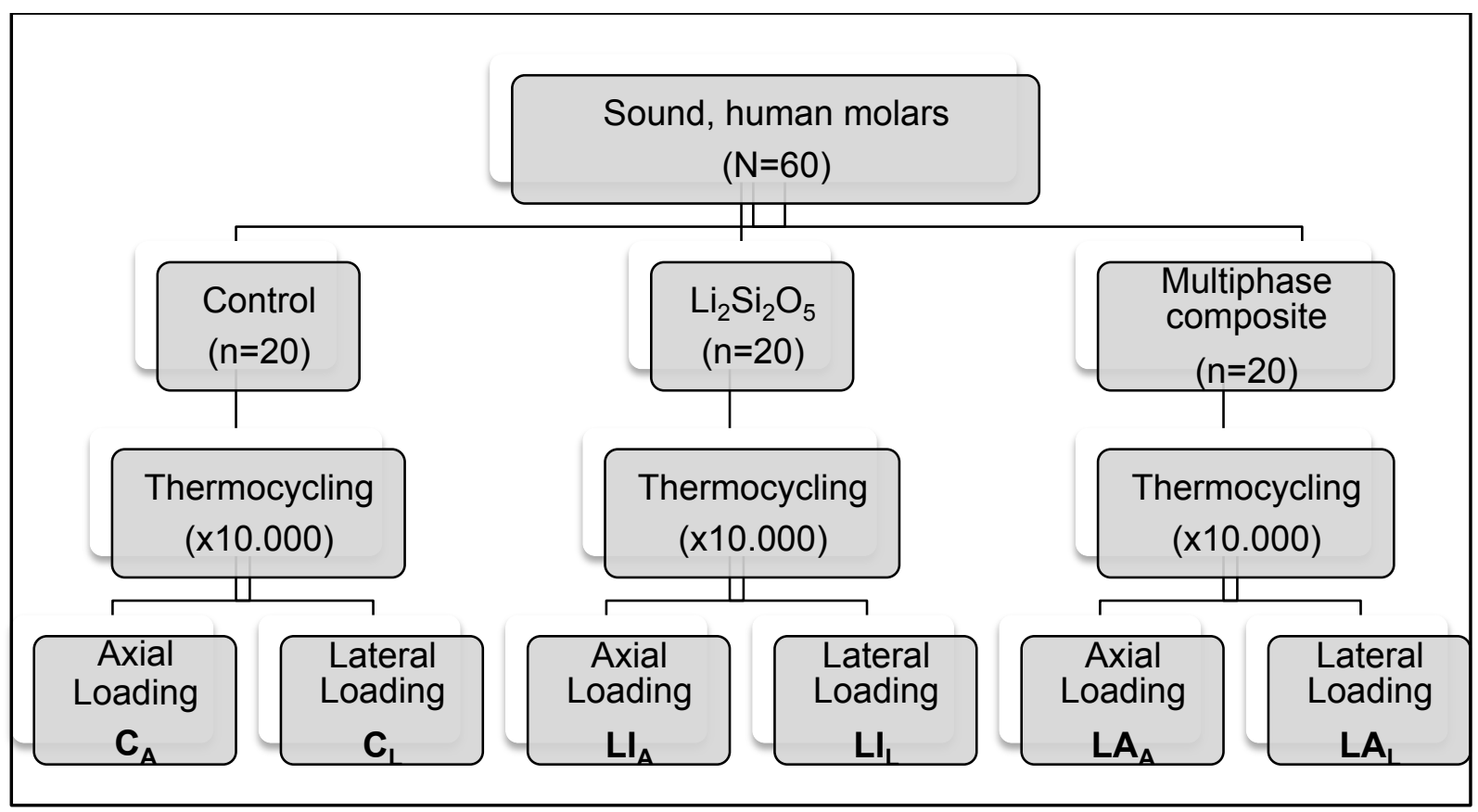

Fig. 1. Flow-chart showing experimental sequence and allocation of groups.

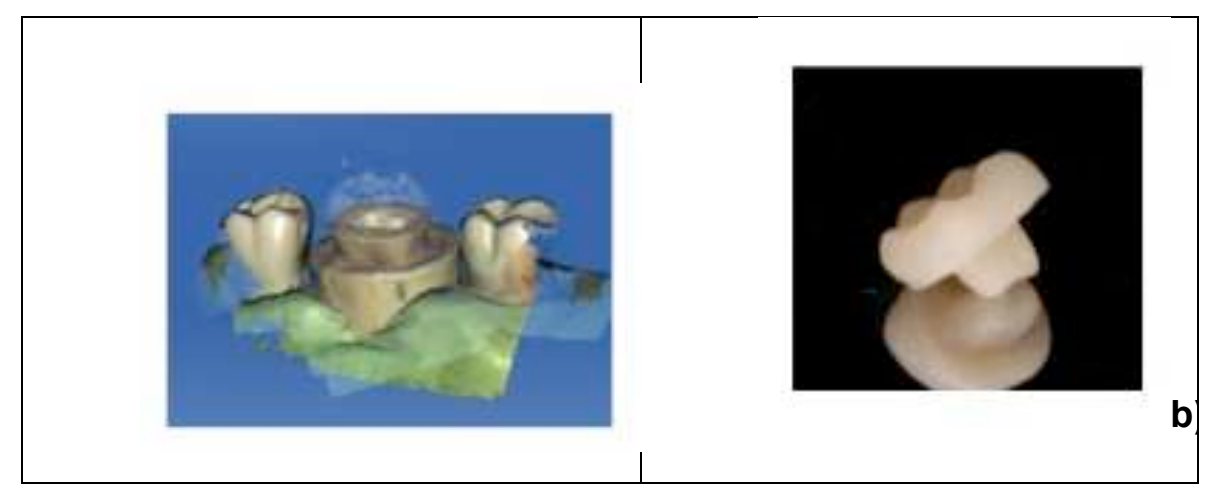

Figs. 2a-b. a) Design of endocrown using the Cerec database (version 3.85, Sirona Dental Systems) to be able to restore the teeth to their original anatomy (Mean mesio-distal length: $10.2 \mathrm{~mm}$, Bucco-palatinal length: $10.2 \mathrm{~mm}$ ) after preparation, b) endocrown after milling (Crown height from fissure to wall preparation outline: $2.5 \mathrm{~mm}$; Endocrown depth from preparation outline to the immediate dentin sealing: $2.3 \mathrm{~mm}$ ). 


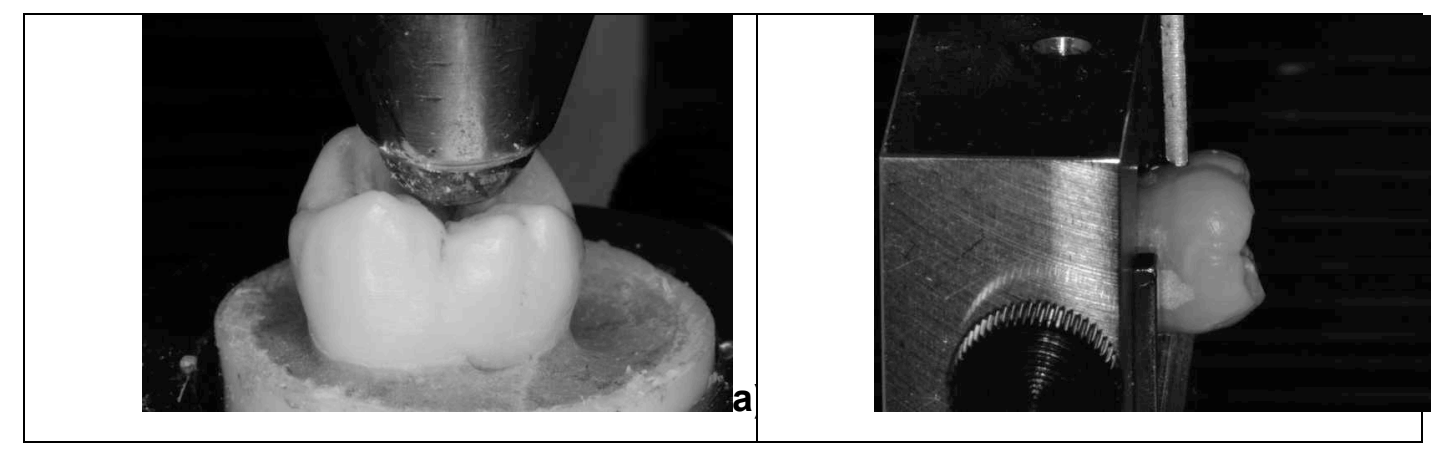

Figs. 3a-b. The position of the load cell in relation to the occlusal surface and to the endocrown-tooth interface during a) axial loading and b) lateral loading, respectively in the universal testing machine where loading was applied until fracture.

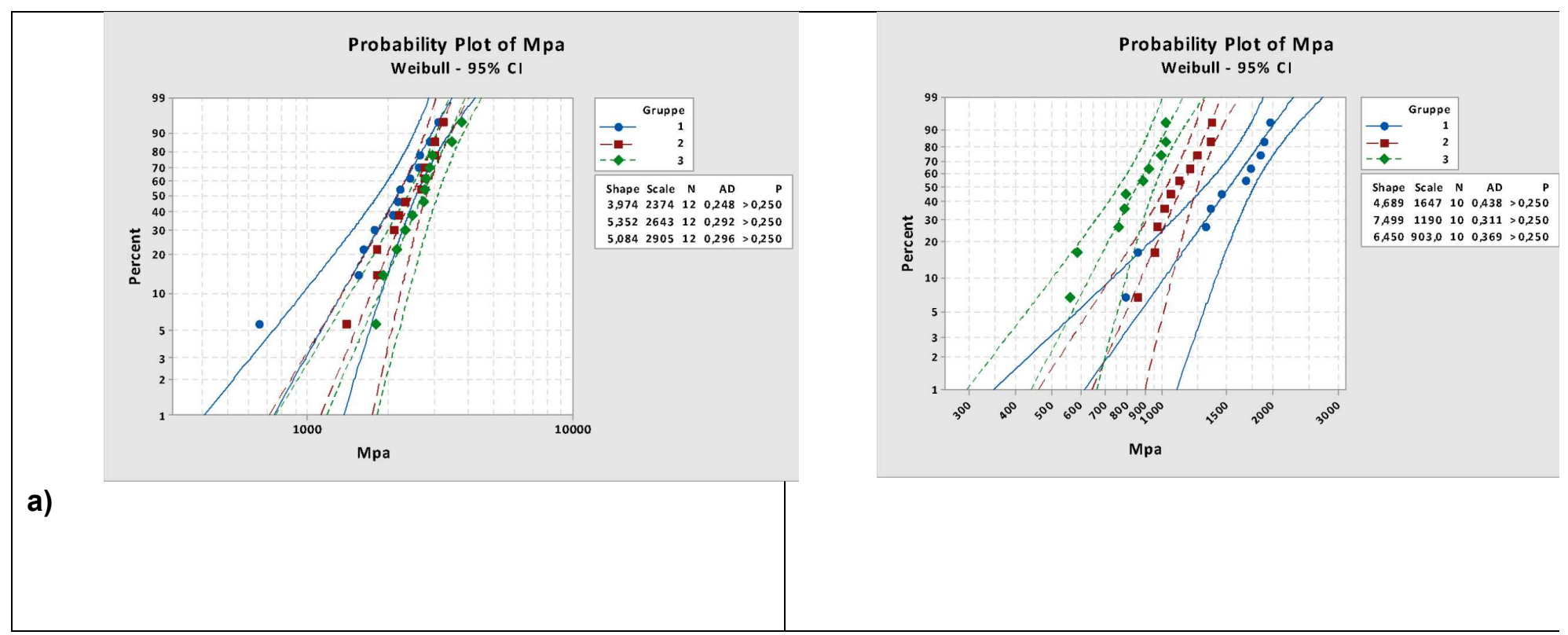

Figs. 4a-b. Probability plot with Weibull curves $(95 \% \mathrm{Cl})$ using maximum likelihood estimation, scale and shape values for all groups after a) axial loading, b) lateral loading. 


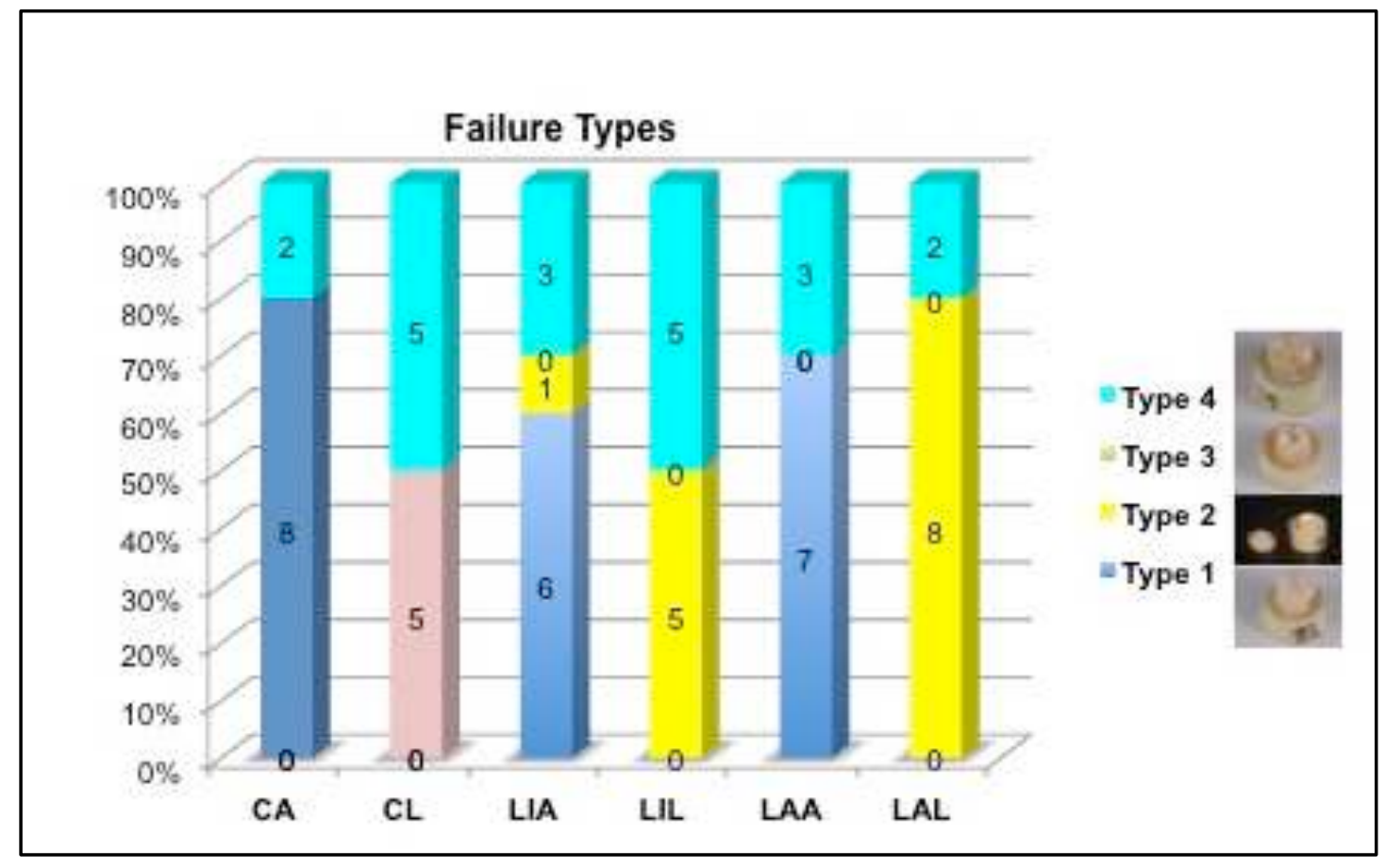

Fig. 5 Frequencies of failure modes in percentages. Type I: Cohesive failure in the endocrown material; Type II: Adhesive failure between the endocrown material and dentin; Type III: Cohesive failure in enamel/dentin; Type VI: Fracture extending to root.

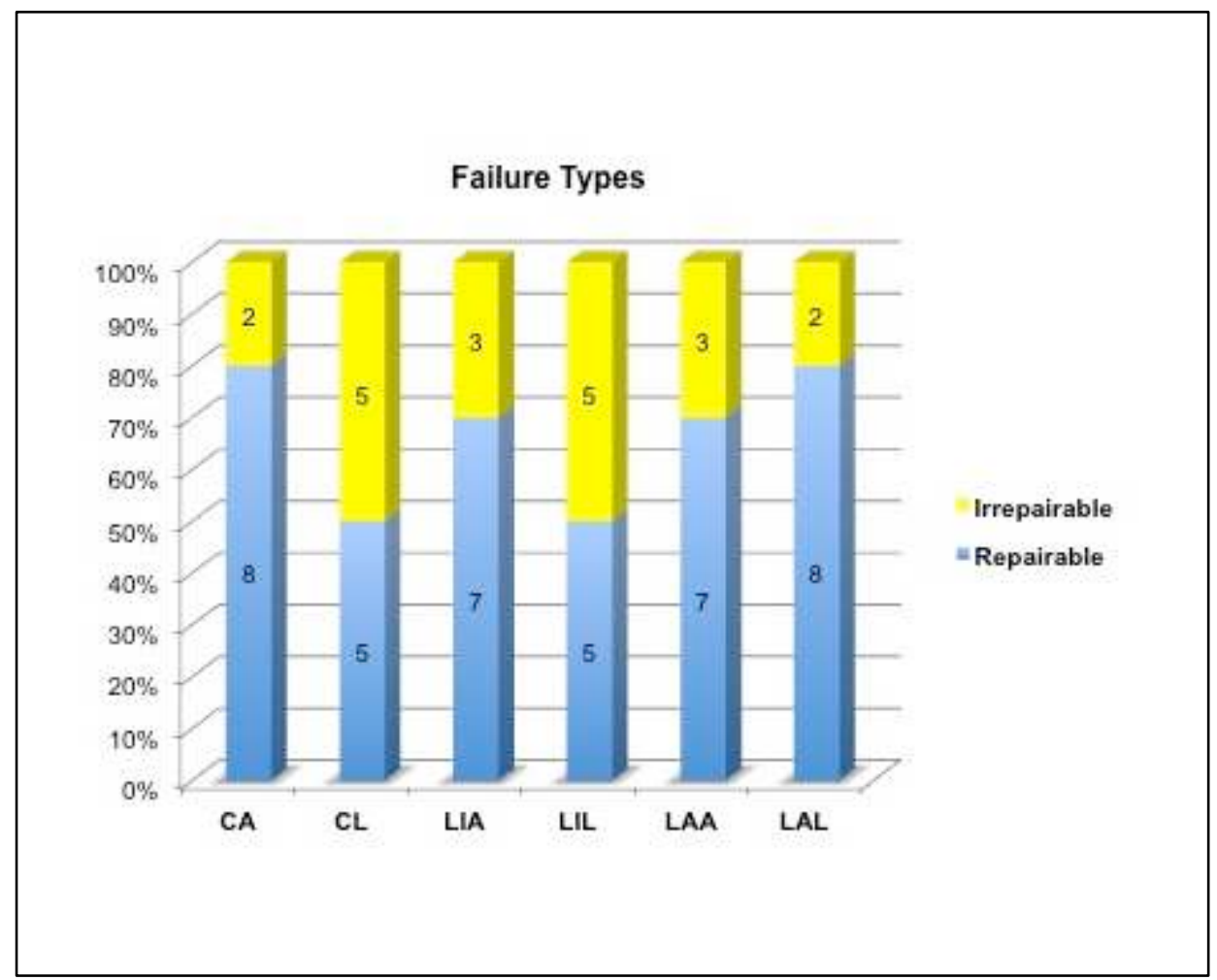

Fig. 6 Frequencies of repairable (above CEJ) and irrepairable (root fractures below CEJ) failures after axial or lateral loading. 